\title{
Design of quad band microstrip patch antenna with slits and slots
}

\author{
Ravikumar Palla ${ }^{*}$ and Dattatre ya Gopi ${ }^{2}$ \\ Department of ECE, G M R Institute of Technology, Rajam, Srikakulam, Andhra Pradesh, India ${ }^{1}$ \\ Department of ECE, Raghu Engineering College (A), Visakhapatnam, India ${ }^{2}$
}

Received: 25-May-2021; Revised: 21-September-2021; Accepted: 23-September-2021

(C)2021 Ravikumar Palla and Dattatreya Gopi. This is an open access article distributed under the Creative Commons Attribution (CC BY) License, which permits unrestricted use, distribution, and reproduction in any medium, provided the original work is properly cited.

\begin{abstract}
Abs tract
Antenna operating in multiple frequency bands has driven the demand of antennas. The design of quad band microstrip patch antenna to attain multiband with improved gain is described in this paper. Several slits and slots are introduced in the design process to allow a sole antenna to operate in multiple bands. Flame Retardant (FR)-4 Epoxy is used as a substrate material due to its low cost and effectiveness than other substrates. The antenna is built and corresponding geometry is simulated in High Frequency Structure Simulator (HFSS) tool, which is based on Finite Element Method (FEM). The operating frequencies of the proposed antenna are $1.8089 \mathrm{GHz}(1.46-2.24 \mathrm{GHz}), 4.64 \mathrm{GHz}(4.57-4.71 \mathrm{GHz})$, $5.3867 \mathrm{GHz}(5.29-5.44 \mathrm{GHz}) \& 12.9778 \mathrm{GHz}(11.36-15.3 \mathrm{GHz})$ with a reflection coefficient observed $-15.59 \mathrm{~dB},-16.55 \mathrm{~dB}$, $-33.15 \mathrm{~dB}$ and $-25.07 \mathrm{~dB}$ respectively. Wide bandwidths $0.7767 \mathrm{GHz}$ and $1.4 \mathrm{GHz}$ are observed for primary and quad bands. Narrow bandwidths are observed for second and third resonant band. The gains are observed as $14.97 \mathrm{dBi}$, 3.81 $\mathrm{dBi}, 4.48 \mathrm{dBi}$ and $3.92 \mathrm{dBi}$ for the respective operating frequencies. The radiation characteristics are observed semi-omni directional and omni-directional for the resonant bands. This antenna can be used in satellite radio, aircraft surveillance and some radar applications.
\end{abstract}

\section{Keywords}

Aircraft surveillance, FR-4 substrate, Gain, Multiband, Radiation patterns, Reflection coefficient.

\section{Introduction}

With the advancement of wireless communication technology, research and design of antennas are attracting more attention. Great progress has been made by the study of microstrip patch antennas when compared to conventional antennas as they have low cost, low profile, light weight and can be fabricated easily. The antenna performance mainly depends on the substrate and its physical configurations. The structure of a rectangular microstrip patch antenna is like a sandwich where the top layer is main patch, the middle part is a substrate and bottom are ground plane. As the antennas are spreads to the new industries like auto mobile, biomedical, satellite communications, it requires more and more frequency bands. Generally, a single antenna will resonate at one frequency, by considering different types of slots and slits it is possible to design an antenna which is resonates at multiple frequencies. A single antenna working for multiple frequencies will reduce the antenna size.

\footnotetext{
*Author for correspondence
}

Based on a wide range of wireless applications and different features, more frequency bands are being used to meet these requirements. Being the use of more frequencies for various applications, the demand for antennas that can operate in multiple frequency bands is increasing.

In order to realize a multi-band antenna in an inadequate area, miniaturization of the antenna is an important issue. Numerous methods have been proposed to achieve multi-band characteristics. One of the methods is to use multiple slots, wherein each slot resonates at a single frequency thus achieving multiple resonances. Maximum of the multi-band antennas in the literature covers the various applications with limited gain, but not suitable for satellite radio, aircraft surveillance and radar applications.

The main objective of this paper is to design a compact quad-band antenna with improved gain and bandwidth. Rectangular slots and slits are considered to optimize the antenna parameters to get the desired band of frequencies. The critical aspect is the 
flexibility, the proposed design is only compatible for the planar structures, and for the curved surfaces it is not compatible as it is not flexible.

\section{Literature review}

There are some techniques for attaining multiband such as using slots on patch, defected ground structure, combination of slots and slits on patch, meandered structure etc. A compact low cost ultrawideband microstrip patch antenna for radar and satellite communication systems [1], which shows multiband characteristics. A wide bandwidth from 5 $\mathrm{GHz}$ to $16 \mathrm{GHz}$ is provided by the modified rectangular radiating material. The tri-band responsive frequency, which covers $\mathrm{C}, \mathrm{X}$ and $\mathrm{Ku}$ bands individually. The frequencies are in the range of 4.9-7 GHz, 7.92-11.08GHz, and 11.85-15.94GHz. Notched band attributes were used to attain multiband response. The design of multiband micro strip patch antenna with the combination of the stub and slot is reported in [2]. A rectangular slot has been cut on the edge of radiating material and a shape of U-slot on the edge of microstrip patch antenna. The length of the slots is nearly a quarter wave. It depicts that by suitable selection of slot dimensions, selecting the path, which is used for a variety of mobile frequency bands. A compact monopole microstrip patch antenna for wideband and multiband applications [3], with a distinct set of frequencies centered at $0.94 \mathrm{GHz}, 2.7 \mathrm{GHz}$, and $4.75 \mathrm{GHz}$ respectively. On the ground plane there exists an Eshaped slot to achieve wideband and multiband operations. All the frequencies can be individually controllable with the help of E-slot parameters. GSM900 which is a low frequency band can be generated with an E-shaped slot in the ground plane. An Industrial, scientific and medical band (ISM band) [4] oriented multiband microstrip patch antenna which serves for a variety of applications. The working frequency range is $902-928 \mathrm{MHz}, 2400$ $2480 \mathrm{MHz}$ and 5150-5350 MHz. The substrate utilized here is Flame Retardant (FR)-4 epoxy, which has a permittivity of 4.4 , the significance of this substrate is low cost and very good mechanical properties. The gain value obtained is $1.34 \mathrm{~dB}, 3.81$ $\mathrm{dB}$, and $4.91 \mathrm{~dB}$ for the above-mentioned set of frequencies.

In reducing the weight, size and power, the antenna design is very critical in space borne applications [5]. Satellite communication bands can be supported by Tightly Coupled Dipole Array (TCDA) and ultrawide band. Which enables in reduction of weight by replacing with multiple antennas, inter-satellite communication can be provided by reutilizing intermediate frequencies from spectral efficiency. Slits, slots have been introduced to make the antenna operate at multiple frequencies [6-10]. A proximitycoupled microstrip antenna [11] has a size of $27 \times 24$ $\mathrm{mm} 2$ consisting of slot and meandered feeder to attain multiple bands for Long Term Evolution (LTE), Bluetooth, Worldwide Interoperability for Microwave Access (Wi-MAX) and Wireless Local Area Network (WLAN) applications is proposed. It is excited electromagnetically by a meander microstrip feed. The impedance matching was achieved by truncating the rectangular patch at a corner and a slot in the center. A bow-tie antenna for Ground Penetrating Radar application [12] is presented, but the presented antenna operates at a single frequency band with a gain of $7 \mathrm{~dB}$. A multi-input multi output antenna with a gain of 3 to $4 \mathrm{dBi}$ to operate at multi frequencies is presented in [13]. The said antenna consists of two radiated elements which are in symmetry to suppress the coupling [14]. An antenna with unidirectional characteristic and a gain of below $10 \mathrm{dBi}$ based on a combination of resonators to achieve multiband is proposed. By varying the strength of coupling between resonant elements, the multiple bands are adjusted. A miniaturized quad band antenna with a peak gain of 1.43 to $3.06 \mathrm{dBi}$ and stable radiation pattern for point-to-point communication is proposed in [15]. Attainment of multiband is done by etching of inverted U-shapes and single fed mechanism. A defected ground structured quad band antenna with a gain range of $2.45 \mathrm{~dB}$ to $4.77 \mathrm{~dB}$ for satellite applications [16] is presented. Periodic square slots are etched on the ground surface to achieve quad band. A multiband is attained by the use of bending structures [17] with a gain of $0.764-4.505 \mathrm{dBi}$ for smart phone applications.

A multi band antenna is proposed [18] for dualpolarization applications. FR-4substrate material and Teflon rivets are used in the antenna design. However, the antenna is bulky and not compatible for compact communication devices. A circular Monopole antenna [19] is proposed for multi-band application. The circular patch is connected using conductive vias. The diameter of the circular patch is $70 \mathrm{~mm}$ and the substrate height is $1.6 \mathrm{~mm}$. A quadband antenna [20] is proposed for mobile phone applications. The size of the antenna is $153 \times 77 \times 0.8$ $\mathrm{mm}^{3}$. The substrate material used FR-4. The system consists of 4 numbers of antenna elements, which increases the bulkiness. A multi-band Microstrip Patch Antenna (MPA) [21] is proposed with nature 
inspired Coyote Optimization Algorithm. Three slits are inserted to get the desired band of frequencies. The patch size is $82.63 \times 44 \mathrm{~mm}^{2}$, which is connected with an $86.4 \times 9.09 \mathrm{~mm}^{2}$ feeder lines. A fork shaped patch antenna [22] is proposed for multi-band applications. The size of the antenna is $50 \times 39 \times 1.6$ $\mathrm{mm}^{3}$. Split ring resonators are used in the ground plane for the best impedance match. A multiband omnidirectional antenna [23] is proposed for railway applications. An asymmetric folded branch was loaded and the slits are considered to achieve multiband frequencies. The sizes of the antenna are 116 $\times 40 \times 1.6 \mathrm{~mm}^{3}$. The Monopole MPA antenna is proposed for multiband applications [24]. The size of the antenna is $53.8 \times 53.8 \mathrm{~mm}^{2}$, and the structure is inspired by multi-cavity magnetron resonator. The frequencies are obtained by considering ring slot with ten small circular cavities.

Design of a single antenna working for multiple frequencies will reduce the overall communication system size. The antennas described above have complex structure, limited gain and fabrication of those antennas are difficult because of complexity in structure. Even if they are fabricated, they are not suitable for satellite radio, aircraft surveillance and some radar applications because of limited gain. As the antenna is a vital element in the communication system, it is very important to design a single antenna working for multiple frequencies with enhanced gain and bandwidth. With the above available literature based on multi band antennas, it is observed that multi band antenna design with enhanced gain and bandwidth is difficult. Very limited work is proposed with a simple multiband antenna design. The design of simple structured antenna having a figure of eight shape, a slot at the top of the patch and full ground at the bottom plane with enhanced gain for satellite radio, aircraft surveillance and radar applications is presented in this paper. The dimensions of the proposed antenna are optimized by an iteration process in simulation. The patch is made of FR-4 substrate material having a permittivity of 4.4 and High Frequency Structure Simulator (HFSS) software is used as a tool to evaluate the performance of the antenna by simulation. The proposed antenna operates at multiple frequencies which covers various bands in the spectrum.

\section{Methodology}

The steps to be followed to design an antenna is:

1. Select the frequency/application for which the antenna is to be designed.
2. Pick the suitable material to design antenna based on profile, size.

3. Select the main dimensions of the antenna as per basic design equations.

4. Design the antenna using any electromagnetic simulation software tool and analyse the design.

5. Fabricate the antenna after attaining the results to meet the application.

The block diagram of an approach to the design of an antenna is shown in Figure 1.

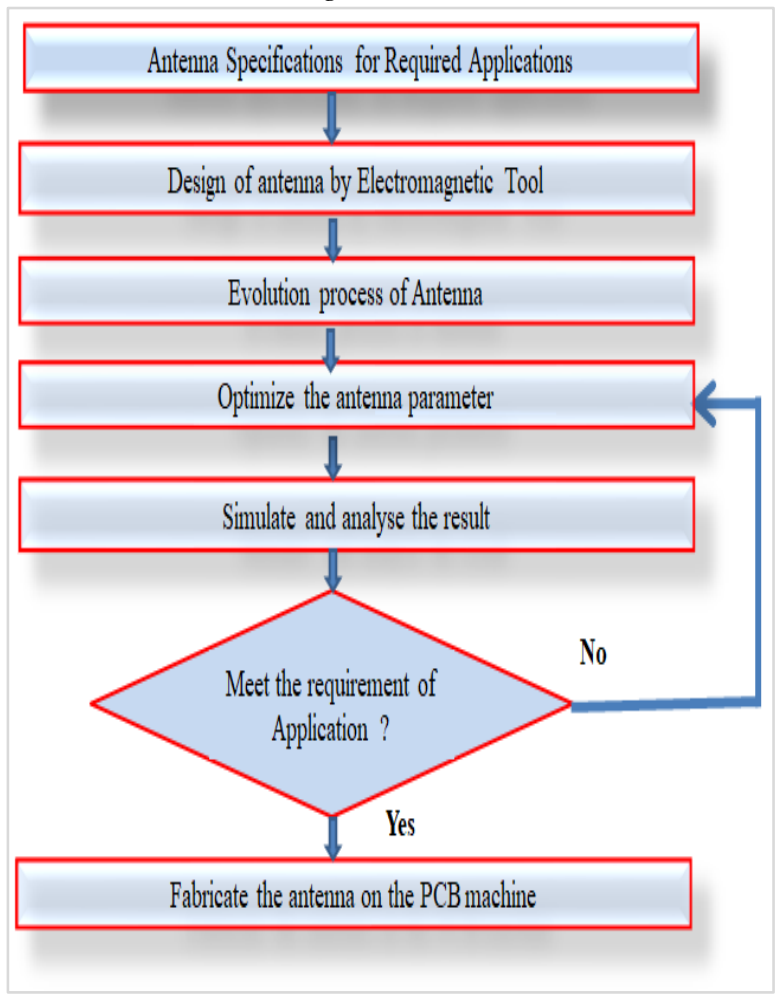

Figure 1 Block diagram of antenna design proces s

\subsection{Antenna design}

The initial geometry of the proposed antenna in evolution process is shown in Figure 2. The prototype is made of FR-4 substrate material having a permittivity of 4.4. Initially the dimensions for one resonant frequency are calculated and the antenna is designed in HFSS software. In order to obtain the required antenna, the design process starts with a basic design. First of all, a design is made with the dimensions of one particular resonating frequency, for instance by considering $10 \mathrm{GHz}$. Then by adding slits to patch at various places and varying its dimensions the desired antenna is acquired as shown in Figure 3 which operates at multiband. The slits introduced cause the variation in current distribution pattern and result in multiband operations. 


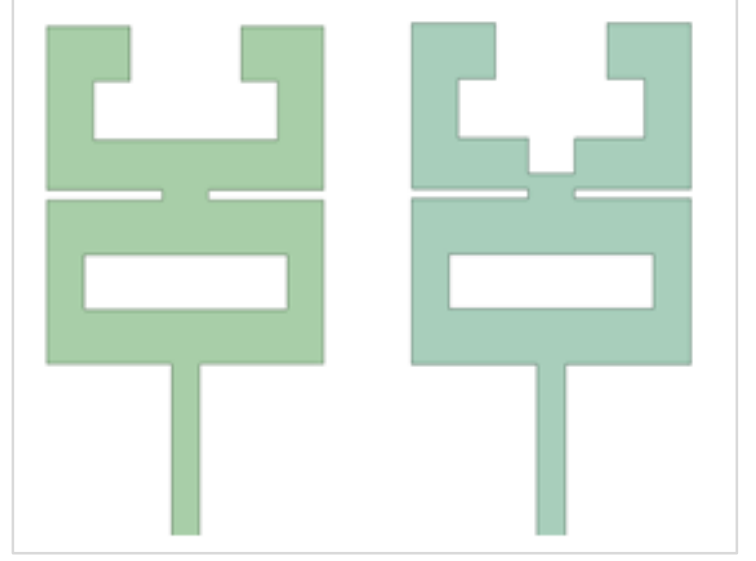

(a)

(b)

Figure 2 Evolution process of antenna (a) stage 1 (b) stage 2

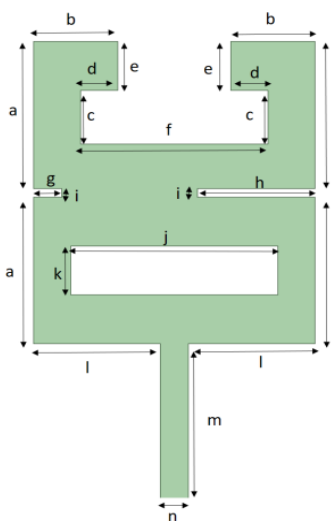

(a)

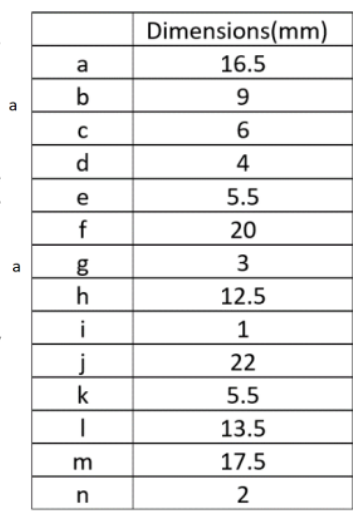

(b)
Figure 3 Final geometry and dimensions of antenna (a) antenna (b) dimensions

\section{Results}

4.1 Reflection coefficient and bandwidth:

When a signal gets reflected due to the discontinuity of the transmission line, the power loss in that particular signal can be represented using reflection coefficient. This discontinuity occurs due to the mismatch of transmission medium. Reflection coefficient helps to know the measure of how well the devices are matched. This parameter is considered as one of the important parameters in analyzing antennas. From the two-port theory the $S$ parameter S11 is also known as reflection coefficient at a single port. $S$ parameter plot can specify the reflection coefficient of the resonating frequencies of an antenna.

Figure 4 shows the frequency vs. reflectance coefficient of the antenna during the evolution process. The antenna in stage 1 resonates at three frequencies with wider bandwidth at $13 \mathrm{GHz}$ with a minimized reflection coefficient of $-32 \mathrm{~dB}$ and lower bandwidth in lower frequency bands. The antenna in stage 2 resonates only at single frequency $7.8 \mathrm{GHz}$ with a reflection coefficient of $-21 \mathrm{~dB}$. Similarly, the reflection coefficient versus frequency of the proposed antenna is shown in Figure 5. The reflection coefficient of the proposed antenna at resonant frequencies is shown in Table 1 and its bandwidth is shown in Table 2. The minimized reflection coefficient of $-33 \mathrm{~dB}$ is observed at 5.38 $\mathrm{GHz}$.

The range of frequencies below $-10 \mathrm{~dB}$ of $\mathrm{S}_{11}$ is generally referred to be antenna impedance bandwidth.

Bandwidth $=$ Upper Cutoff Frequency - Lower Cutoff Frequency

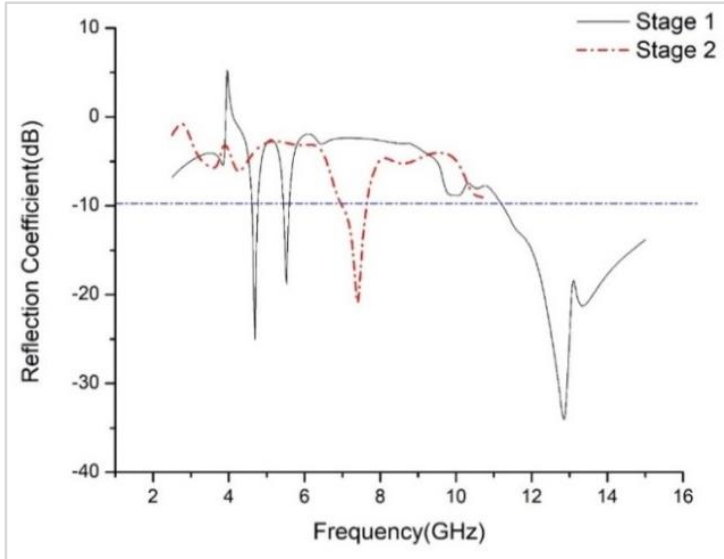

Figure 4 Plot of S11 of antenna in evolution process

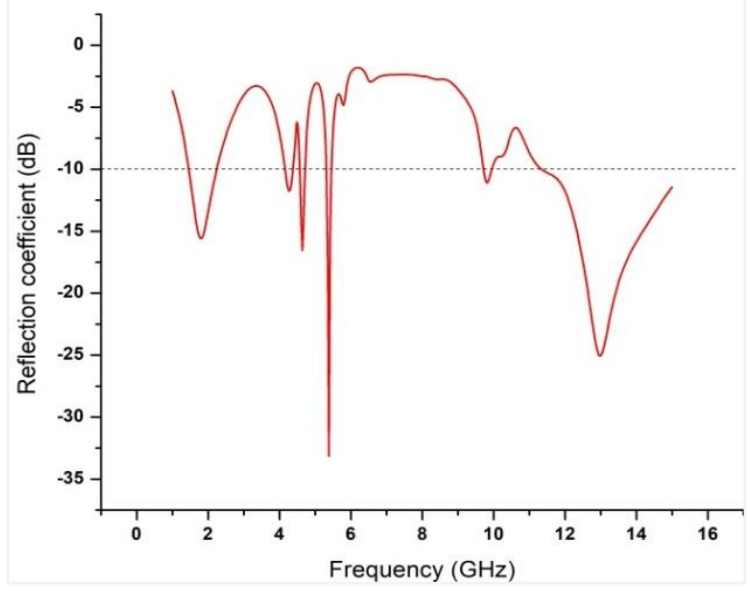

Figure 5 Plot of the reflection coefficient of proposed antenna 
Table 1 Operating frequencies

\begin{tabular}{ll}
\hline Frequency in GHz & Reflection coefficient $($ in $\mathbf{~ d B})$ \\
\hline 1.8089 & -15.5992 \\
\hline 4.64 & -16.5533 \\
\hline 5.3867 & -33.1510 \\
\hline 12.9778 & -25.0706 \\
\hline
\end{tabular}

Table 2 Bandwidth at their frequencies

\begin{tabular}{llll}
\hline $\begin{array}{l}\text { Frequency } \\
\text { (GHz) }\end{array}$ & UCF & LCF & BW(GHz) \\
\hline 1.8089 & 2.2444 & 1.4677 & 0.7767 \\
\hline 4.64 & 4.7122 & 4.5788 & 0.1334 \\
\hline 5.3867 & 5.4489 & 5.2933 & 0.1556 \\
\hline 12.9778 & 15.3 & 11.36 & 1.4 \\
\hline
\end{tabular}

\subsection{Directivity}

The direction of antenna radiation pattern can be represented using directivity. If the directivity is 1 , then the radiation pattern of the antenna is equal in all directions. Directivity is the measure of radiation pattern directionality of an antenna. If the radiation is equal in all the directions, then the antenna is said to have zero directionality and the corresponding directivity will be 1 which is $0 \mathrm{~dB}$. The transmitted or received strength of a signal from/to an antenna is represented using this parameter. The below radiation patterns from Figure 6 to Figure 9 are observed for $\varnothing$ $=90^{\circ} \& \theta=90^{\circ}$ at the corresponding resonant frequencies. The null point is observed in the direction of $150^{\circ}$ for H-plane and omni directional pattern is observed for E-plane at $1.8089 \mathrm{GHz}$ frequency. Maximum radiation is observed symmetrically in the direction of $315^{\circ}$ and $45^{\circ}$ for Eplane at $4.64 \mathrm{GHz}$.

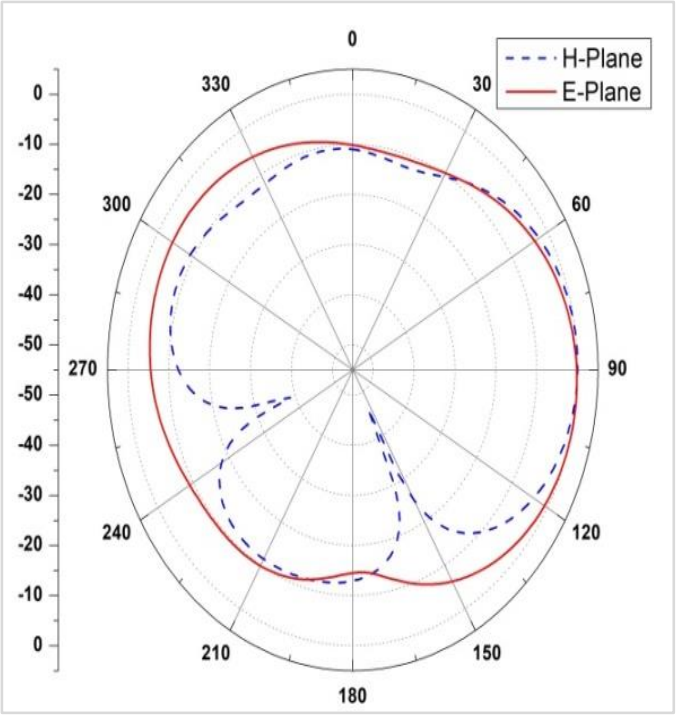

Figure 6 Radiation pattern at $1.8089 \mathrm{GHz}$

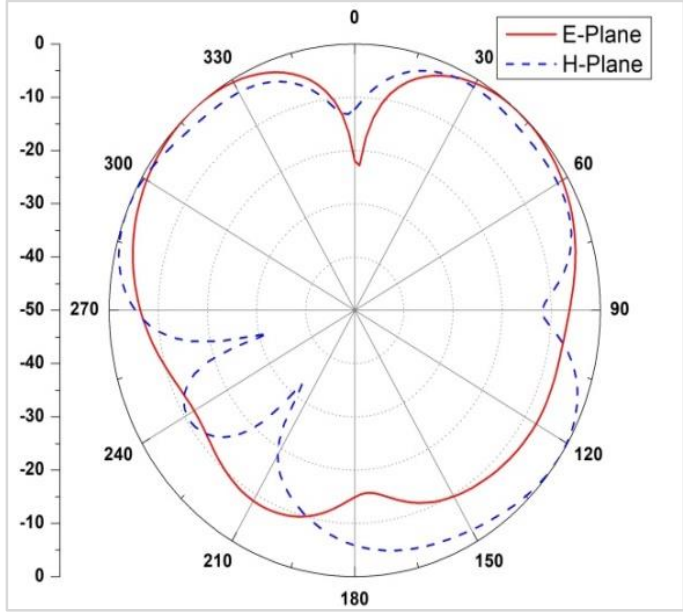

Figure 7 Radiation pattern at $4.64 \mathrm{GHz}$

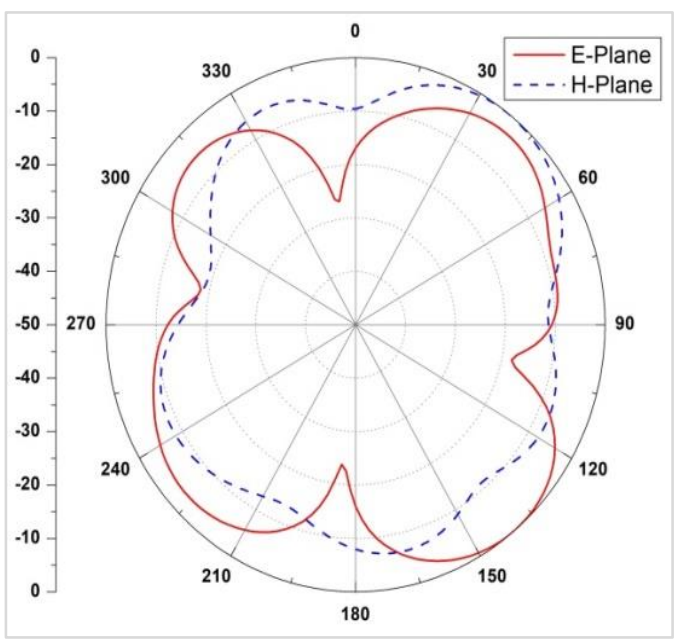

Figure 8 Radiation pattern at $5.3867 \mathrm{GHz}$

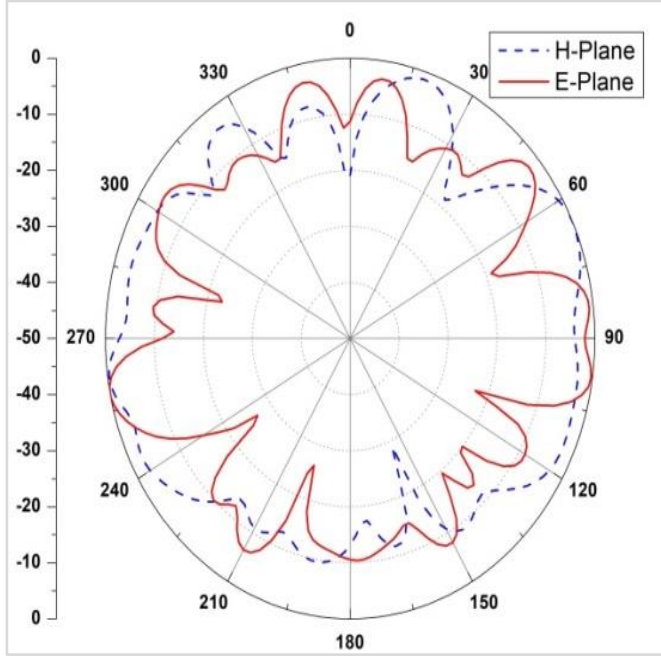

Figure 9 Radiation pattern at $12.9778 \mathrm{GHz}$ 
4.3Antenna gain

The gain of an antenna tells the magnitude of the transmission power in the direction where the peak radiation is occurred with reference to an isotropic source. Simply it indicates the strength of the antenna in sending or receiving a signal in the indicated direction of the path. Basically, antenna gain is most commonly considered in an antenna's specification than directivity because the antenna gain takes actual losses that occur into account. The antenna gains at operating frequencies of the proposed antenna are shown in Figures 10 to Figure 13. It is observed that maximum gain of $14.97 \mathrm{dBi}$ at $1.8 \mathrm{GHz}$ as shown in Figure 10. The maximum gain of $14.97 \mathrm{~dB}$ is attained for a frequency $1.8089 \mathrm{GHz}$ in the direction of $\varnothing=60^{\circ} \& \theta=90^{\circ}$, for $4.64 \mathrm{GHz}$ is $3.81 \mathrm{~dB}$ in the direction of $\varnothing=270^{\circ} \& \theta=300^{\circ}$, for $5.3867 \mathrm{GHz}$ is $4.48 \mathrm{~dB}$ at approx. $\varnothing=170^{\circ} \& \theta=300^{\circ}$, and for $12.9778 \mathrm{GHz}$ is $3.92 \mathrm{~dB}$ at approx. $\emptyset=0^{0} \& \theta=5^{0}$ as shown in the Figure 10 to Figure 13. The gain and directivity are related as:

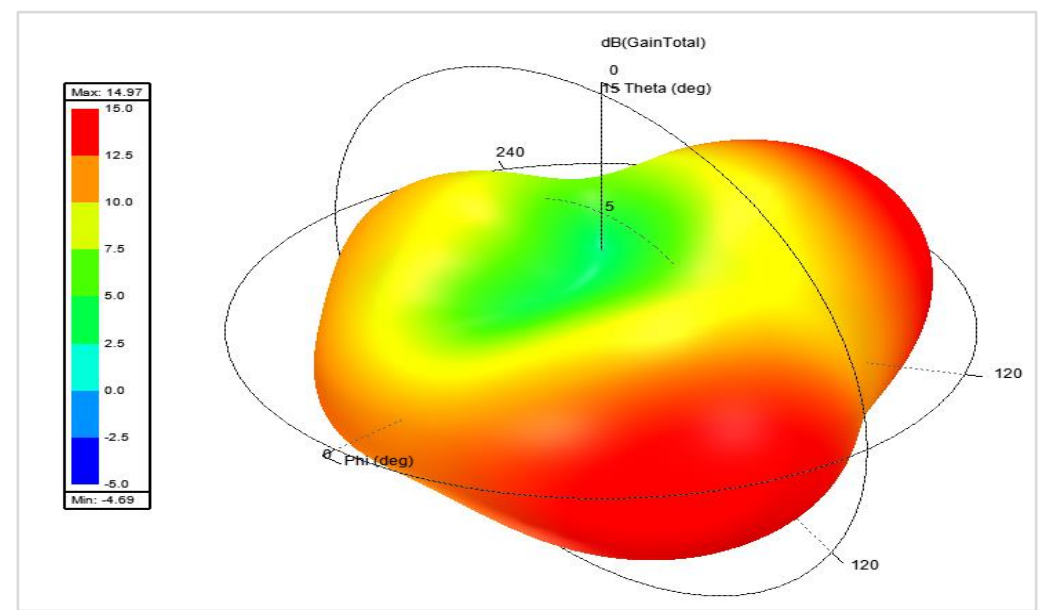

Figure 10 3-D radiation pattern at $1.8089 \mathrm{GHz}$

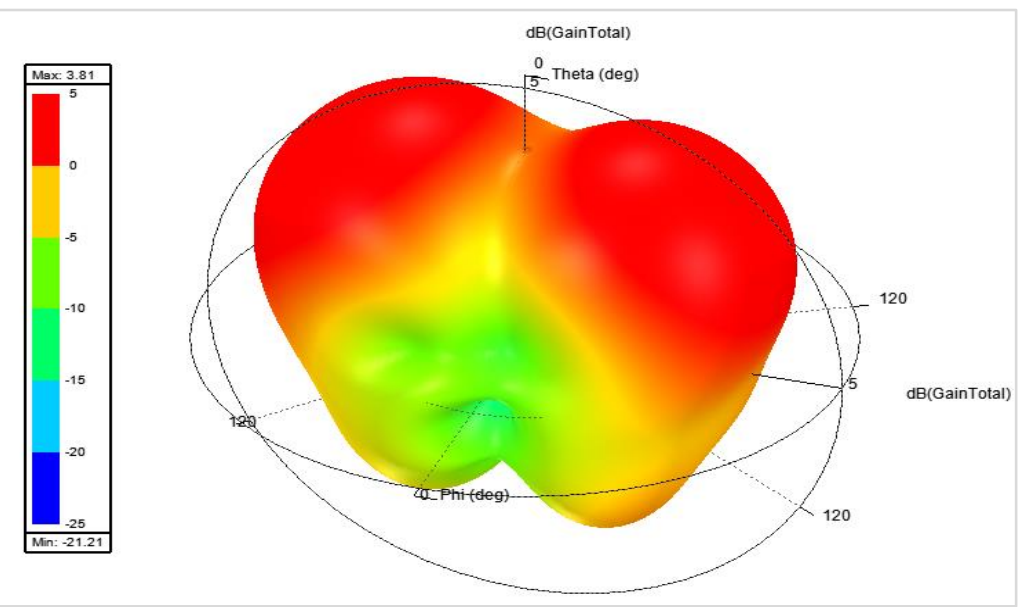

Figure 11 3-D radiation pattern at $4.64 \mathrm{GHz}$

Gain $=$ Efficiency $\times$ Directivity 


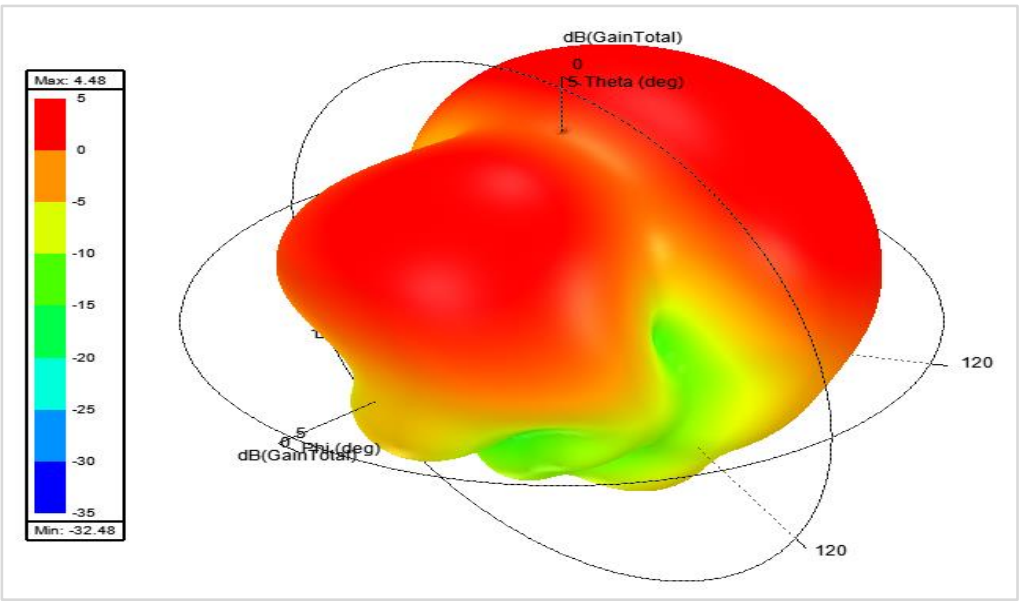

Figure 12 3-D Radiation pattern at $5.3867 \mathrm{GHz}$

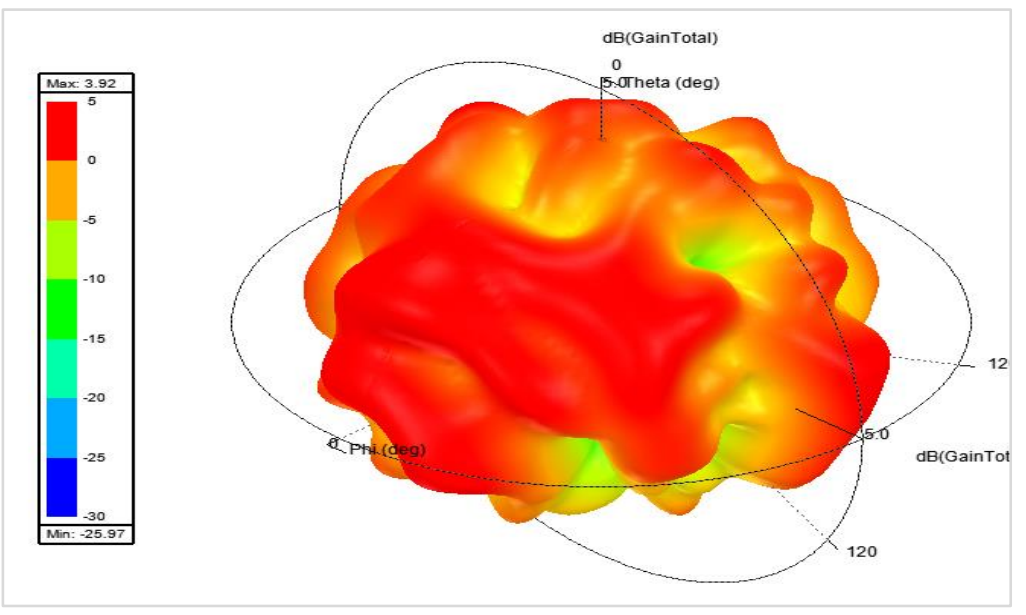

Figure 13 3-D radiation pattern at $12.9778 \mathrm{GHz}$

\section{Discussion}

It is observed from the results that the antenna resonates at multi frequencies with enhanced gain to be suitable for satellite and RADAR applications. Multiband is obtained by using slots and slits on the patch. It is seen that combination of omnidirectional and semi omni directional pattern is attained. Table 3 shows the comparison of performance among the antenna models which are exist in the literature and that of proposed antenna. Most of the antennas in the literature are designed for FR-4 substrate material. It is observed from the Table 3 that the proposed antenna gives a maximum gain of $14.97 \mathrm{dBi}$, which is very more when compared to the existing antennas.

\subsection{Limitations}

The proposed antenna operates at multiband with narrow impedance bandwidth at lower frequency bands and the antenna is not conformal which are preferable to integrate the satellites, Global Position System (GPS), RADAR applications.

Table 3 Performance comparis on of antenna models

\begin{tabular}{|c|c|c|c|c|c|}
\hline Ref. No. & Substrate & $\begin{array}{l}\text { No. of resonant } \\
\text { frequencies }\end{array}$ & $\begin{array}{l}\text { Antenna dimension } \\
(\mathrm{mm}\end{array}$ & Microwave bands & $\begin{array}{l}\text { Maximum gain } \\
\text { (dBi) }\end{array}$ \\
\hline [11] & FR-4 & 4 & $27 \times 24$ & $\mathrm{~S}, \mathrm{C}$ bands & 4.5 \\
\hline [13] & FR-4 & 4 & $60 \times 80$ & $\mathrm{~L}, \mathrm{~S}$ bands & $3-4$ \\
\hline$[14]$ & Rogers & 4 & $50 \times 50$ & $\mathrm{C}$ band & 9 \\
\hline [15] & F4B & 4 & $40 \times 40$ & $\mathrm{~S}, \mathrm{C}$ bands & $1.43-2.39$ \\
\hline
\end{tabular}




\begin{tabular}{|c|c|c|c|c|c|}
\hline Ref. No. & Substrate & $\begin{array}{l}\text { No. of resonant } \\
\text { frequencies }\end{array}$ & $\begin{array}{l}\text { Antenna dimension } \\
(\mathrm{mm}\end{array}$ & Microwave bands & $\begin{array}{l}\text { Maximum gain } \\
\text { (dBi) }\end{array}$ \\
\hline$[17]$ & FR-4 & 3 & $95 \times 60$ & L, S bands & $0.764-4.505$ \\
\hline$[21]$ & FR-4 & 4 & $82 \times 86$ & L, S bands & 3.94 \\
\hline Proposed & FR-4 & 4 & $51 \times 29$ & L, C, Ku bands & 3.81-14.97 \\
\hline
\end{tabular}

\section{Conclusion and future work}

A design and analysis of rectangular micro-strip patch antenna which can be operated at multiple bands is done in HFSS software. It is observed from the analysis that by embedding slits and a slot on the patch, the antenna functions at numerous frequencies like $1.8089 \mathrm{GHz} \quad(1.46-2.24 \mathrm{GHz}), 4.64 \mathrm{GHz}$ (4.57$4.71 \mathrm{GHz}), \quad 5.3867 \quad \mathrm{GHz} \quad(5.29-5.44 \mathrm{GHz}) \quad \& \quad 12.9778$ $\mathrm{GHz}(11.36-15.3 \mathrm{GHz})$ with a reflection coefficient observed $-15.59 \mathrm{~dB},-16.55 \mathrm{~dB},-33.15 \mathrm{~dB}$ and -25.07 $\mathrm{dB}$ respectively. The gains are observed as $14.97 \mathrm{dBi}$, $3.81 \mathrm{dBi}, 4.48 \mathrm{dBi}$ and $3.92 \mathrm{~d} \mathrm{Bi}$ for the respective operating frequencies. The several uses of the proposed antenna are like GPS carriers, Satellite Mobile phones and RADAR. The research can be extended to wearable antennas using flexible substrate materials.

\section{Acknowledgment}

The authors would like to thank the editor and reviewers whose comments and suggestions helped in increasing the quality of the manuscript.

\section{Conflicts of interest}

The authors have no conflicts of interest to declare.

\section{References}

[1] Naghar A, Aghzout O, Essaaidi M, Alejos A, Sanchez $\mathrm{M}$, Falcone F. Ultra wideband and tri-band antennas for satellite applications at $\mathrm{C}-, \mathrm{X}-$, and $\mathrm{Ku}$ bands. In proceedings of mediterranean microwave symposium 2014 (pp. 1-5). IEEE.

[2] Deshmukh AA, Ray KP. Multiband rectangular microstrip antennas. IETE Journal of Research. 2011; 57(5):437-42.

[3] Abutarboush HF, Nasif H, Nilavalan R, Cheung SW. Multiband and wideband monopole antenna for GSM900 and other wireless applications. IEEE Antennas and Wireless Propagation Letters. 2012; 11:539-42.

[4] Lubis MA, Zulkifli FY, Rahardjo ET. Design of multiband microstrip antenna for industrial, scientific, and medical band application. In international symposium on electronics and smart devices 2016 (pp. 343-6). IEEE.

[5] Novak MH, Volakis JL. Ultrawideband antennas for multiband satellite communications at $\mathrm{UHF}-\mathrm{Ku}$ frequencies. IEEE Transactions on Antennas and Propagation. 2015; 63(4):1334-41.

[6] Naik KK, Dattatreya G, Chaitanya RP, Palla R, Rani SS. Enhancement of gain with corrugated Y-shaped patch antenna for triple-band applications. International Journal of RF and Microwave ComputerAided Engineering. 2019; 29(3).

[7] Palla R, Naikketavath K. Multiband rectangular microstrip patch antenna operating at $\mathrm{C}, \mathrm{X} \& \mathrm{Ku}$ bands. In third international conference on multimedia processing, communication \& information technology 2020 (pp. 19-25). IEEE.

[8] Kim JW, Jung TH, Ryu HK, Woo JM, Eun CS, Lee DK. Compact multiband microstrip antenna using inverted-L-and T-shaped parasitic elements. IEEE Antennas and Wireless Propagation Letters. 2013; 12:1299-302.

[9] Koutinos AG, Anagnostou DE, Joshi R, Podilchak SK, Kyriacou GA, Chryssomallis MT. Modified easy to fabricate E-shaped compact patch antenna with wideband and multiband functionality. IET Microwaves, Antennas \& Propagation. 2018; 12(3):326-31.

[10] Dattatreya G, Naik KK. Tri-band miniaturized elliptical shaped flexible patch antenna for wireless communications at S-band applications. International Journal of Microwave and Optical Technology. 2019; 14(1):37-45.

[11] Bakariya PS, Dwari S, Sarkar M, Mandal MK. Proximity-coupled multiband microstrip antenna for wireless applications. IEEE Antennas and Wireless Propagation Letters. 2014; 14:646-9.

[12] Barkataki N, Tiru B, Sarma U. Performance investigation of patch and bow-tie antennas for ground penetrating radar applications. International Journal of Advanced Technology and Engineering Exploration. 2021; 8(79):753-65.

[13] Yang Y, Chu Q, Mao C. Multiband MIMO antenna for GSM, DCS, and LTE indoor applications. IEEE Antennas and Wireless Propagation Letters. 2016; 15:1573-6.

[14] Mao CX, Gao S, Wang Y, Sanz-izquierdo B. A novel multiband directional antenna for wireless communications. IEEE Antennas and Wireless Propagation Letters. 2016; 16:1217-20.

[15] Boukarkar A, Lin XQ, Jiang Y, Yu YQ. Miniaturized single-feed multiband patch antennas. IEEE Transactions on Antennas and Propagation. 2016; 65(2):850-4.

[16] Prasad BS, Prasad MV. Design and analysis of compact periodic slot multiband antenna with defected ground structure for wireless applications. Progress in Electromagnetics Research M. 2020; 93:77-87.

[17] Dong J, Yu X, Deng L. A decoupled multiband dualantenna system for WWAN/LTE smartphone applications. IEEE Antennas and Wireless Propagation Letters. 2017; 16:1528-32. 
[18] Wen H, Qi Y, Weng Z, Li F, Fan J. A multiband dualpolarized omnidirectional antenna for 2G/3G/LTE applications. IEEE Antennas and Wireless Propagation Letters. 2017; 17(2):180-3.

[19] Chapari A, Nezhad AZ, Firouzeh ZH. Analytical investigation of a low-profile multiband circular microstrip antenna with monopolelike radiation patterns. IEEE Transactions on Antennas and Propagation. 2018; 66(12):6810-7.

[20] Huang D, Du Z, Wang Y. A quad-antenna system for 4G/5G/GPS metal frame mobile phones. IEEE Antennas and Wireless Propagation Letters. 2019; 18(8):1586-90.

[21] Boursianis AD, Papadopoulou MS, Pierezan J, Mariani VC, Coelho LS, Sarigiannidis P, et al. Multiband patch antenna design using nature-inspired optimization method. IEEE Open Journal of Antennas and Propagation. 2020; 2:151-62.

[22] Chiang B, Lynch MJ, Wood DH, inventors; IPR Licensing Inc, assignee. Multi-band antenna for wireless applications. United States Patent US 7,268,731. 2007.

[23] Cui J, Zhang A, Chen X. An omnidirectional multiband antenna for railway application. IEEE Antennas and Wireless Propagation Letters. 2019; 19(1):54-8.

[24] Hammas HA, Hasan MF, Jalal AS. Compact multiband microstrip printed slot antenna design for wireless communication applications. Advanced Electromagnetics. 2020; 9(2):52-9.

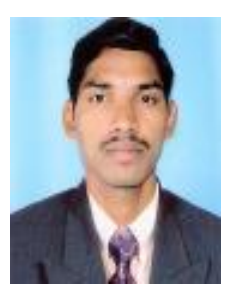

Dr. Ravikumar Palla received the B.Tech degree in 2005 in Electronics and Communication Engineering (ECE) from JNTU College of Engineering, Kukatpally, Hyderabad, India. M.Tech degree in RADAR and Microwave Engineering from Andhra University, Visakhapatnam, Andhra Pradesh, India in 2010. He got Ph.D degree in 2020 from K $\mathrm{L}$ deemed to be University, Andhrapradesh, India. Currently he is working as Assistant Professor in the department of ECE, GMRIT, Rajam, Srikakulam, Andhra Pradesh, India. His research interests include microstrip antennas, FSS, conformal antennas and wearable antennas. Email: ravikumar.p@gmrit.edu.in

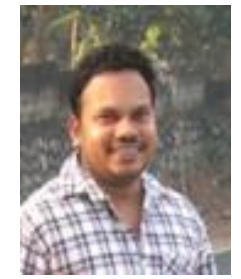

Dr. Dattatreya Gopi was born in India, A.P, in 1987. He received B. Tech in Electronics and Communication Engineering (ECE) from Jawaharlal Nehru Technological University, Kakinada, A.P, India, and M. Tech in Radar and Microwave Engineering (R\&M) from Andhra University College of Engineering (A), Visakhapatnam. He got his Ph.D in the field of antennas from $\mathrm{K} \mathrm{L}$ deemed to be University, KLEF, Guntur, A.P, India. He worked as JRF and SRF for the sponsored project funded by the Department of Science and Technology (DST). Currently he is working as Associate Professor in the Department of ECE, Raghu Engineering College (A), Visakhapatnam, India. He has published 19 papers in reputed International/ National Journals/ Conferences. His research interests include flexible antennas, concentric circular ring antennas, conformal antennas, biomedical antennas and Textile antennas.

Email: dattatreya.gopi@gmail.com

\begin{tabular}{lll} 
Appendix I & & \\
\hline S. No. & Abbre viation & Description \\
\hline 1 & FEM & Finite Element Method \\
\hline 2 & FR-4 & Flame Retardant-4 \\
\hline 3 & GPS & Global Position System \\
\hline 4 & HFSS & $\begin{array}{l}\text { High Frequency Structure } \\
\text { Simulator }\end{array}$ \\
\hline 5 & ISM & $\begin{array}{l}\text { Industrial, Scientific and } \\
\text { Medical }\end{array}$ \\
\hline 6 & LCF & Lower Cut-off Frequency \\
\hline 7 & LTE & Long Term Evolution \\
\hline 8 & MPA & Microstrip Patch Antenna \\
\hline 9 & RADAR & RAdio Detection And Ranging \\
\hline 10 & TCDA & Tightly Coupled Dipole Array \\
\hline 11 & UCF & Upper Cutoff Frequency \\
\hline 12 & UWB & Ultra-Wide Band \\
\hline 13 & Wi-MAX & Worldwide Interoperability for \\
& & Microwave Access \\
\hline & WLAN & Wireless Local Area Network \\
\hline
\end{tabular}

